\title{
Editorial e carta do editor em revista: considerações dialógicas
}

DOI: http://dx.doi.org/10.21165/el.v49i3.2678

\section{Lorenna Mayara Fornel ${ }^{1}$}

\section{Resumo}

Este artigo tem por objeto o estudo dos gêneros do discurso editorial e carta do editor em revistas, desenvolvido a partir das reflexões do Círculo de Bakhtin. Nesse sentido, analisaremos duas cartas do editor da revista impressa Realidade, em sua $1^{\mathrm{a}}$ e $6^{\mathrm{a}}$ edição publicadas no ano de 1966 e dois editoriais da revista impressa Fórum em sua edição 120, de outubro de 2013, e 168, publicada em outubro de 2014. A partir desta seleção, os objetivos são evidenciar as estabilidades e instabilidades dos gêneros a fim de identificar a relação entre esses gêneros; analisar as relações dialógicas do momento sócio-históricocultural e do projeto de dizer das revistas; verificar aspectos relacionados ao público-alvo, às ideologias e ao estilo dessas instituições, os quais interferem nas alterações existentes nos editoriais de ambos veículos. Para esta análise, consideramos as reflexões do Círculo de Bakhtin a partir das concepções de gêneros do discurso, ideologia, estilo e dialogismo. Esta discussão é um recorte da dissertação de mestrado em desenvolvimento intitulada "Editorial e carta do editor: uma análise dialógica do discurso".

Palavras-chave: editorial; estudos bakhtinianos do discurso; estilo; esfera jornalística.

1 Universidade Estadual Paulista "Júlio de Mesquita Filho", Araraquara, São Paulo, Brasil; lorenna.fornel@unesp.br; https://orcid.org/0000-0001-5029-0083 


\title{
Editorial and editor's letter in magazines: dialogical considerations
}

\begin{abstract}
This article's topic is the study of genres of discourse editorialand editors'letter in magazines, developed by the perspectives of Bakhtinian studies. In this way, we are going to analyze two editors' letters of Realidade printed magazine, in $1^{\mathrm{a}}$ and $6^{\mathrm{a}}$ edition, published in 1966, and two editorials of Fórum magazine in edition 120, of March 2013, and 168, published in October 2014. Come from this selection, we aim to evidence the stabilities and instabilities of the genres to identify the relation of these genres; analyze the dialogical relations of the social historic moment and the saying project of the magazines; verify aspects related to the audience, the ideological and the stylistic aspects of such magazines, which interfere in the changes in both vehicles' editorials. For this analysis, we consider the reflections of Bakhtin Circle from the conceptions of genres of discourse, ideology, style, and dialogism. This discussion is a cut of the Master's degree in development "Editorial and editor's letters: a dialogical analysis of discourse".
\end{abstract}

Keywords: editorial; Bakhtinian studies of discourse; style; journalistic sphere.

\section{Os gêneros discursivos carta do editor e editorial na formação de opinião}

O presente artigo propõe a reflexão acerca dos gêneros discursivos editorial e carta do editor nas revistas Realidade e Fórum, a partir da compreensão de que estes são textos opinativos inseridos na esfera jornalística e visam auxiliar a formação da opinião pública. Ao depararmo-nos com as finalidades destes gêneros, entendemos que, nas revistas analisadas, há um projeto de dizer que oferece uma prévia do conteúdo da edição para o leitor e apresenta o posicionamento da instituição acerca das temáticas discutidas.

Diante das reflexões sobre os gêneros discursivos e a esfera jornalística, tal análise dos editoriais e carta do editor foi motivada pela indagação de como estes se constituem e de que modo se dá a articulação do posicionamento da instituição, visto que na linguagem, pautada na concepção bakhtiniana, todo enunciado é ideológico. O jornalismo tem por sua essência refletir uma realidade, mas também, sob a perspectiva de Bakhtin, entendemos que esta refrata o corpo social de acordo com as concepções do periódico, de modo a difundir a informação e a opinião sobre a realidade para seus leitores. Com isso, os diversos gêneros discursivos presentes neste meio têm como tentativa difundir a informação da realidade e formar a opinião pública, como é evidente nos gêneros carta do editor e editorial. 
Objetivamos, assim, evidenciar as estabilidades e instabilidades dos gêneros, assim como a relação que há entre esses; identificar as recorrências que permitem verificar o público-alvo e o estilo dos veículos. Para isso, foram selecionadas duas cartas do editor publicadas nas edições de número 1 e 6 da revista Realidade, datados da década de 60, e dois editoriais da revista Fórum em suas publicações 120, no ano de 2013, e 168, de 2014. 0 recorte foi selecionado de modo qualitativo, com o objetivo de destacar as principais recorrências nas revistas em relação à apresentação do posicionamento das instituições e às aproximações entre os gêneros.

Desse modo, para a fundamentação teórica, pautamo-nos nas reflexões bakhtinianas sobre gêneros do discurso, diálogo, estilo e ideologia com o fito de compreendermos como estes enunciados se constituem e suscitam os valores ideológicos concebidos pelas instituições. Ainda, para tal verificação e análise da relação entre os enunciados, concebemos o cotejamento como método, com o cotejo entre os editoriais e as cartas do editor a fim de compreendermos que, em épocas diferentes, esses possuem estabilidades e instabilidades que possibilitam diferenciá-los.

Esse trabalho é um recorte das discussões desenvolvidas na pesquisa de mestrado em andamento "Editorial e carta do editor: uma análise dialógica do discurso", orientada pela Profa. Dra. Marina Célia Mendonça.

\section{Reflexões acerca dos gêneros do discurso na esfera jornalística}

As reflexões do Círculo de Bakhtin² concebem que um gênero discursivo é constituído de uma forma composicional, estilo e tema. Em relação à forma, numa concepção inicial, pensamos na organização textual deste enunciado; para o estilo e tema vamos pensar nas escolhas linguísticas e nos sentidos daquele enunciado. Assim, Bakhtin define que o emprego da língua se dá por meio de enunciados e, nas diversas esferas de atividades humanas, constitui os gêneros discursivos, os quais cumprem com as situações discursivas.

O emprego da língua efetua-se em forma de enunciados (orais e escritos) concretos e únicos, proferidos pelos integrantes desse ou daquele campo da atividade humana. Esses enunciados refletem as condições específicas e as finalidades de cada referido campo não só por seu conteúdo (temático) e pelo estilo da linguagem, ou seja, pela seleção dos recursos lexicais, fraseológicos e gramaticais da língua, mas, acima de tudo, por sua construção composicional. (BAKHTIN, 2003, p. 261).

2 As questões de autoria possuem grande discussão, para isso, aqui assumimos o termo Círculo ou até mesmo Bakhtin para se referir aos estudos desenvolvidos pelo grupo russo. 
Os enunciados inserem-se em uma formação social de presente, passado e futuro (BUBNOVA, 2015). Como presente, concebe-se aquilo que está evidente no corpo social atual, ao que é passado, tem-se a retomada de enunciados de dado momento histórico na atualidade e, para o futuro, compreendem-se as utopias. A partir desses pressupostos, verificamos a recorrência do dialogismo, conceito refletido pelo círculo que caracteriza a teoria bakhtiniana, o qual consiste no diálogo entre enunciados, uma vez que este só é constituído a partir de outros no elo interminável da cadeia comunicativa.

A palavra diálogo, ao contrário, é bem entendida, no contexto bakhtiniano, como reação do eu ao outro, como "reação da palavra à palavra de outrem", como ponto de tensão entre o eu e o outro, entre círculos de valores, entre forças sociais. A essa perspectiva interessa não a palavra passiva e solitária, mas a palavra na atuação complexa e heterogênea dos sujeitos sociais, vinculada a situações, a falas passadas e antecipadas. (MARCHEZAN, 2006, p. 123).

Todo enunciado por si é dialógico, pois retoma outros proferidos anteriormente, assim as palavras se tornam um território comum entre o eu e o outro (VOLÓCHINOV, 2017). O círculo, ao se propor a discutir o caráter dialógico dos enunciados, analisa a relação entre eu-outro, em que a alteridade é o norte de discussão, tendo em vista que o indivíduo se constitui como sujeito do enunciado a partir das interações estabelecidas com seu outro em determinado contexto, o que remete ao projeto de dizer posto.

Ao analisar o enunciado concreto, inserido em uma dada situação comunicativa, o círculo postula a atuação de forças centrípetas e centrífugas. Assim, diante determinada conjuntura em que há um conjunto de discursos que são considerados "mais aceitos", estabelece-se a atuação de forças centrípetas, que centralizam um ideário, geralmente constituído de valorações conservadoras. Paradoxalmente, quando um enunciado estabelece um embate entre tais vozes centralizadoras, há a ação de forças centrífugas, as quais descentralizam e desconstroem os ideais tradicionalmente aceitos.

Não há neutralidade no jogo das vozes. Ao contrário, ele tem uma dimensão política, uma vez que as vozes não circulam fora do exercício do poder: não se diz o que quer, quando se quer, como se quer. Não se trata apenas da atuação do campo tradicional da política, ou seja, a esfera do Estado; estão em causa todas as relações de poder, desde as do dia-a-dia até aquelas do exercício do poder do Estado. (FIORIN, 2006, p. 31).

Ainda sobre os enunciados, segundo Bakhtin, estes são individuais e sociais, pois "o filósofo mostra que a maioria absoluta das opiniões dos indivíduos é social" (FIORIN, 2006, p. 33), surgem das vivências no contexto e direcionam-se a partir da identidade dos destinatários destes, os quais carregam valores, ideologias e participam de grupos sociais. Dessa forma, conclui-se que não há enunciado neutro, livre de ideologias e não 
pode ser considerado apenas individual. Todo aspecto de constituição do enunciado remete a um contexto e, portanto, um enunciado deve ser analisado "na sua historicidade, na sua concretude, para deixar ver mais do que a dimensão exclusivamente linguística e/ou sua fragmentação" (BRAIT, 2005b, p. 71) e perceber a que se dirige e a ideia que se quer transmitir por meio dele.

Nas esferas comunicativas, cada enunciado vai se caracterizar por uma temática, ou seja, pelo conteúdo abordado, assim como a maneira como este é trabalhado, o estilo, o qual é construído a partir do indivíduo inserido no social, portanto, é individual e social concomitantemente. As escolhas lexicais e a entonação e entoação dão o tom valorativoexpressivo que caracterizam o estilo do enunciado. Tais escolhas, assim como exposto, reiteram a atuação extra verbal dos participantes da comunicação com o intuito de cumprir as especificidades exigidas pelo gênero no projeto de dizer do sujeito. Assim, em cada esfera, os enunciados se organizam de modo a efetivar sua proposta enunciativa, como é possível analisar ao verificar os enunciados do jornalismo.

A esfera jornalística, em uma definição breve, está calcada pela organização de gêneros que estabelecem a finalidade de levar o conhecimento da realidade à massa por meio da disseminação de fatos recorrentes no dia a dia do corpo social. Desse modo, por meio de uma diversidade de gêneros como reportagem, notícia, entrevista, editorial e artigo de opinião, estabelece-se um elo comunicativo entre os veículos e a população, seja por intermédio de discursos orais, verbais ou verbo-visuais. Para isso, cada gênero se organiza a partir de enunciados estruturados a fim de cumprir sua função comunicativa, como o editorial e carta do editor, objetos de estudo deste trabalho, os quais cumprem a função de evidenciar e explicitar a opinião do veículo. Nesses gêneros, há um sujeito que é representante da redação do suporte jornalístico - revistas ou jornais - que mediante uma linguagem objetiva esclarece para o leitor os objetivos a serem cumpridos na edição e posiciona-se de acordo com os projetos de dizer do veículo.

Tais gêneros possibilitam a explicitação de posicionamentos, rompendo com uma visão equivocada, já rompida na contemporaneidade, de que o discurso jornalístico é imparcial e visa à neutralidade. É importante ressaltar, nesse ínterim, que apesar de ser impossível estabelecer um discurso livre de valores, assim como discute o Círculo de Bakhtin, o jornalismo privilegia enunciados estilisticamente objetivos, por exemplo, com o uso de verbos na voz passiva sintética, os quais remetem a uma tentativa de promover um tom de impessoalidade ao discurso.

As definições estilísticas, ainda, estão atreladas com a temática abordada em cada enunciado, assim, no jornalismo, tais escolhas evidenciam um posicionamento do veículo, pois um tema pode ser tratado de diversas maneiras a partir do que a esfera em que está inserida quer transmitir ao seu enunciatário. As mídias possuem características exclusivas, apesar de buscarem um mesmo objetivo: informar, formar opinião e impor 
ideais evalores. Cada qual, inserida no contexto sócio-histórico, possui um posicionamento inserido na sociedade, seja ele político, social, econômico ou cultural, que caracteriza a ideologia de seus discursos veiculados.

Com isso, podemos afirmar que, na busca de convencer o leitor, concretiza-se o discurso a ser expresso quando o tom valorativo-expressivo, formado a partir das escolhas linguísticas, alcança seu interlocutor. Tal alcance, na esteira das reflexões bakhtinianas, pode se dar por uma concordância, mas também pela discordância do enunciado.

Compreendemos que a opinião faz parte da esfera jornalística e que há gêneros que possibilitam essa manifestação, garantindo o acesso do público ao posicionamento das instituições. Os gêneros discursivos no jornalismo desenvolvem um projeto de dizer voltado às intenções que são propostas pela instituição responsável. Entendemos que os gêneros aqui em questão são responsáveis por expressar diretamente a opinião das empresas jornalísticas. Sendo assim, neste momento definimo-los para compreendermos as aproximações e distanciamentos entre editorial e carta do editor, visto que ambos pertencem ao jornalismo opinativo.

O gênero editorial abrange a apresentação da opinião da instituição jornalística e, assim como discute Marques de Melo (1985), é dirigido para constituir a opinião pública, consequentemente, dedica-se à coletividade. No Brasil, as instituições estabelecem no editorial um diálogo com as acepções da esfera política, visto que as empresas integram os interesses políticos aos corporativos que defendem. Desse modo, o editorial faz parte de um projeto da instituição de apresentar seu posicionamento para a população seguindo os pressupostos que regulamentam o Estado.

Os editoriais são organizados pela diretoria das instituições, os responsáveis pela redação das edições, e são analisados e revisados para que se mantenha a organização coerente com as propostas do veículo informativo. Marques de Melo (1985) estabelece uma vasta análise de como se dá a produção destes gêneros e explicita que, em determinados momentos, os jornais e revistas eram dirigidos por pequenos grupos e assim os textos eram assinados pelos próprios donos, fator que se altera nos editoriais contemporâneos em que as grandes corporações é que são responsáveis e assim não há a expressão da opinião do diretor de redação, mas da corporação que vai divulgar a edição.

Ao analisar a estrutura do editorial, concebendo aqui os pressupostos bakhtinianos em relação às estabilidades que definem um gênero discursivo, pode-se afırmar que este é um enunciado organizado a partir do projeto de dizer da revista, faz uso de linguagem formal e impessoal e apresenta no desenvolvimento o que será discutido na edição da revista. A partir desses pressupostos, Marques de Melo (1985) esclarece quatro atributos que constituem este gênero: 
1) Impessoalidade: não é atribuída uma assinatura, utiliza-se a terceira pessoa do singular ou a primeira do plural;

2) Topicalidade: possui uma delimitação temática, mesmo sem o domínio do público ainda, visto que a revista apresenta os assuntos que ainda serão retratados na edição por meio deste gênero;

3) Condensabilidade: há ênfase às afirmações, evitando detalhamentos e demonstrações;

4) Plasticidade: possibilidade de mudança e flexibilidade do conteúdo.

Diante detais atributos, entende-se comoé apresentado um editorial, quais as estabilidades deste gênero que compõe o corpus do trabalho. Evidenciamos a seguir a carta do editor e as características que a qualificam como tal. A carta do editor também é um gênero discursivo que tem por finalidade apresentar os conteúdos que serão retratados na edição da revista de modo resumido e evidenciar para o leitor os posicionamentos da instituição. O interlocutor apresentado no enunciado é o chefe de redação da revista, responsável por organizar e selecionar os fatos reportados na edição, assim, dispõe-se de um discurso objetivo e pautado no projeto de estabelecer contato com seu leitor. Silva (2011, p. 68), ao realizar a análise das cartas do editor sob uma perspectiva histórica, pontua que essas "buscavam divulgar a opinião do jornal sobre determinado assunto, mas a partir de aspectos formais típicos de uma carta (por exemplo, um destinatário explícito e a assinatura do responsável pela carta)".

Nas discussões sobre o jornalismo opinativo, Marques de Melo (1985) esclarece que as revistas com temáticas culturais ou políticas privilegiam o uso de editoriais, enquanto periódicos de informações gerais escolhem cartas dos editores, definindo estas como "merchandising" jornalístico. Diante de tal definição, entendemos que "merchandising" define as cartas como um gênero que visa convencer e evidenciar para o leitor a relevância da instituição ao apresentar o conteúdo que será veiculado na edição. Além disso, Silva (2011) aponta que as cartas do editor estão vinculadas à tradição do gênero epistolar e por isso se aproximam do leitor ao evidenciar a assinatura do editor responsável, garantindo que este é um representante da instituição.

A partir de tais perspectivas, objetivamos verificar as proximidades e distanciamentos entre o gênero carta do editor e editorial em revistas a partir da análise de como se concretizam esses gêneros na esfera jornalística brasileira, uma vez que ambos são definidos como enunciados que visam evidenciar as informações que serão desenvolvidas na edição e trazem o posicionamento da instituição. Assim, podemos verificar que, a partir das concepções de Marques de Melo (1985) e Silva (2011), temos as seguintes especificidades dos gêneros carta do editor e editorial, que posteriormente serão verificadas por meio da análise dos textos apresentados pelas revistas Realidade e Fórum: 
Quadro 1. Os gêneros discursivos carta do editor e editorial

\begin{tabular}{|c|l|l|}
\hline $\begin{array}{c}\text { GÊNERO } \\
\text { DISCURSIVO }\end{array}$ & \multicolumn{1}{|c|}{ FUNÇÃo JORNALÍSTICA } & \multicolumn{1}{|c|}{ ESPECIFICIDADES } \\
\hline Carta do Editor & $\begin{array}{l}\text { Apresentar as informações que serão } \\
\text { retratadas na edição de modo objetivo } \\
\text { a fim de esclarecer, denunciar ou } \\
\text { defender a instituição acerca do tema } \\
\text { abordado na edição. }\end{array}$ & $\begin{array}{l}\text { Para Silva (2011), é um texto que se } \\
\text { aproxima da carta, por isso assinado, } \\
\text { para estabelecer um vínculo com o } \\
\text { leitor. } \\
\text { Para Marques de Melo (1985), trata- } \\
\text { se de um merchandising jornalístico, o } \\
\text { qual tem como finalidade promover a } \\
\text { instituição em pauta. }\end{array}$ \\
\hline Editorial & $\begin{array}{l}\text { Texto de opinião voltado para a a } \\
\text { apresentação do posicionamento da } \\
\text { instituição acerca das discussões em } \\
\text { pauta na sociedade, com o objetivo } \\
\text { de convencer o leitor da opinião } \\
\text { apresentada. }\end{array}$ & $\begin{array}{l}\text { Marques de Melo (1985) caracteriza } \\
\text { o editorial como um texto impessoal; } \\
\text { plástico, visto que está condicionado } \\
\text { aos temas em questão, mas sempre } \\
\text { objetiva manter o posicionamento da } \\
\text { instituição. }\end{array}$ \\
\hline
\end{tabular}

Fonte: Elaboração própria

\section{O editorial e a carta do editor em uma perspectiva dialógica}

Diante das reflexões postuladas sobre os gêneros discursivos e os aspectos relevantes da esfera jornalística, explicitamos parte da análise desenvolvida na nossa pesquisa que foi apresentada no $67^{\circ}$ Seminário do GEL. Faz-se necessário ressaltarmos que, a partir dos pressupostos bakhtinianos, conceberemos o cotejamento como procedimento de análise, verificando os diálogos existentes entre os gêneros discursivos aqui analisados a fim de compreendermos a constituição destes na esfera jornalística e os discursos sociais evidenciados nos enunciados, verificando o contexto de produção, como disserta Geraldi (2012, p. 33, grifos do autor):

Dar contextos a um texto é cotejá-lo com outros textos, recuperando parcialmente a cadeia infinita de enunciados a que o texto responde, a que se contrapõe, com quem concorda, com quem polemiza, que vozes estão aí sem que se explicitem porque houve esquecimento ou origem.

O corpus a ser analisado traz dois editoriais da revista Fórum, publicados no meio digital, e duas cartas do editor veiculadas nas edições impressas 1 e 6. Como critério de seleção das revistas, foram utilizadas Realidade e Fórum, as quais possuem uma aproximação ideológica, ao buscarem trabalhar em suas edições temas políticos voltados ao social. 
A revista Realidade, financiada pela editora Abril, circulou durante a década de 60, desde 1966, e encerrou suas atividades em 1976. Ao analisar suas edições, verifica-se que abordava um jornalismo literário, com matérias detalhadas e a evidência de uma atuação jornalística investigativa. Em um momento histórico de ditadura militar, em que a mídia foi fortemente atacada pela censura, a revista contestou o poder vigente e, com isso, em algumas edições, não pôde ter circulação. A seguir, tem-se a carta do editor, como foi intitulada, da edição número 1 de abril de 1966, a qual traz a abertura da circulação da nova revista na época:

Temos o prazer de apresentar o primeiro número de REALIDADE, novo lançamento da Editora Abril. Há 16 anos vimos editando revistas para o público brasileiro, acompanhando a extraordinária evolução do País. O Brasil vai crescendo em todas as direções. Voltado para o trabalho e confiante no futuro, prepara-se para olhar de frente os seus muitos problemas a fim de analisá-los e procurar solucionálos. E é por isso que agora surge REALIDADE. Será a revista dos homens e das mulheres inteligentes que desejam saber mais a respeito de tudo. Pretendemos informar, divertir, estimular e servir a nossos leitores com seriedade, honestidade e entusiasmo. Queremos comunicar a nossa fé inabalável no Brasil e no seu povo, na liberdade do ser humano, no impulso renovador que hoje varre o País, e nas realizações da livre iniciativa. Assim é com humildade, confiança e prazer que dedicamos REALIDADE a centenas de milhares de brasileiros lúcidos, interessados em conhecer melhor o presente para viver melhor o futuro. (REALIDADE, abril de 1966a, p. 3).

Na página que apresenta a carta citada, há no final do texto a assinatura do editor chefe Victor Civita, responsável pela organização da edição. Diante dos pressupostos do gênero discursivo editorial, a primeira indagação que surge é a escolha por apresentar "carta do editor", o que já pode evidenciar a tentativa de aproximação do seu leitor. Além disso, são expostos, como uma edição de inauguração, os objetivos da revista em relação ao seu público "Pretendemos informar, divertir, estimular e servir a nossos leitores", o que é uma evidência do projeto de dizer.

Nesse sentido, na esteira das análises bakhtinianas do discurso, verifica-se um tom valorativo nacionalista no discurso de esperança e confiabilidade, "fé inabalável no Brasil e no seu povo", que a revista quer propor ao seu leitor, caracterizado como "homens e mulheres que desejam saber mais a respeito de tudo". Nessas escolhas, reflete-se um projeto de dizer que mostra a quem se dirige e o que a revista está propondo: uma abordagem complexa, quando traz os adjetivos "inteligentes" e "lúcidos" que estarão dispostos a ter acesso a uma informação de confiança, como evidenciam.

A seguir, tem-se a carta do editor publicada na edição 6 de setembro de 1966, a qual trata da proibição pelo poder público de uma matéria desenvolvida pela revista que 
analisava a questão da sexualidade na juventude. Em oposição à edição 1, que tratava da inauguração da edição e das perspectivas que a revista tinha em relação ao seu público, a seguir é possível verificar que o veículo busca aproximar o leitor, mas agora trazendo um tom de oposição à realidade posta:

Neste número, REALIDADE, ia concluir a publicação da grande pesquisa focalizando o que os jovens pensam, fazem e falam a respeito de sexo. Poucos dias antes da impressão da segunda parte de "A juventude diante do sexo", entretanto, recebemos uma advertência do Exmo. Sr. Alberto Cavalcanti de Gusmão, Juiz de Menores da Guanabara, comunicando-nos que apreenderia a edição, caso publicássemos a conclusão da pesquisa. Na opinião do Juiz, o artigo era "obsceno e chocante". Ao nosso ver, não pode haver obscenidade num artigo que é apenas o retrato fiel do comportamento e das atitudes de uma parte representativa da juventude brasileira. Não inventamos este retrato. Também não o aprovamos, nem condenamos. Isso cabe aos nossos leitores. Mas estamos serenos por tê-lo divulgado, prestando aos pais, educadores e, sobretudo, aos jovens um serviço que julgamos inestimável - e imprescindível. Não querendo, mesmo assim, entrar em choque com o Juizado de Menores da Guanabara, resolvemos suspender temporariamente a publicação da parte final do trabalho, até que os Tribunais Superiores se pronunciem a respeito. REALIDADE parte do princípio de que seus leitores são adultos, inteligentes e interessados em saber a verdade. E continuará fiel ao seu compromisso de informar. Com imparcialidade, com serenidade. E com a coragem de enfrentar os fatos. (REALIDADE, setembro de 1966b, p. 3).

Ao analisarmos tal enunciado, ressalta-se a aproximação da revista com o leitor, fator característico do gênero discursivo quando se analisa que o locutor busca se justificar e se posicionar diante da barbaridade de proibir a explanação de um conteúdo de importância social, tendo em vista os problemas que são decorrentes da juventude diante o sexo. Com isso, pode-se afırmar a recorrência da atuação de uma força centrípeta, calcada no ideário conservadorista da sociedade de considerar temas relacionados ao sexo como um "tabu social", enquanto o discurso da revista, que busca romper com este estereótipo e tratar com seriedade a problemática, atua como força centrífuga ao romper com tal visão. Nesse ínterim, ainda notamos que a revista tem um posicionamento de oposição em relação à ideologia posta pelo poder público, reiterando a parcialidade do enunciado.

Assim como na edição de número 1, há a recorrência de manter um elo com o leitor e postular a confiabilidade que a revista quer transmitir ao público, por meio das escolhas lexicais "E continuará fiel ao seu compromisso de informar. Com imparcialidade, com serenidade". Com a análise das duas cartas do editor, é explícito o aspecto estilístico do veículo de prometer ao leitor o cumprimento de seus objetivos, tendo em vista que é reiterada em ambas edições, ao final do texto, a preocupação em manter um jornalismo fiel ao seu público. 
Para analisarmos algumas estabilidades e instabilidades do gênero, foi selecionada a revista Fórum, a qual é publicada desde 2001 nas versões impressa e desde 2014 somente on-line, buscando noticiar os acontecimentos na sociedade e uma discussão pautada no ideal de que "é na multiplicidade de vozes que se faz um mundo melhor" (FÓRUM, on-line, 2019), evidenciando um posicionamento axiológico que valoriza o social e sua pluralidade como fator de identidade da revista. Suas edições eram publicadas mensalmente e passaram a ser divulgadas semanalmente. A seguir, o editorial da edição 120, publicada na plataforma digital:

"Primeira coisa que se pensa: segurança. Segurança é polícia, entre um cantor de rap, um padre e um policial, ele [o cidadão] vai eleger um policial. O voto explica." É assim que o músico Mano Brown, capa desta edição, toca em um dos pontos mais importantes na pauta política brasileira, a violência. É também uma reflexão a respeito de como a sociedade enxerga e lida com esse problema, buscando sempre ações conservadoras e de cunho repressivo que, inevitavelmente, se voltam contra ela mesma.

Esse é um dos aspectos que teimam em não mudar naquilo que Brown chama de "novo Brasil" que nasce. Um país que conseguiu reduzir a pobreza e que trouxe algum conforto material a classes historicamente excluídas, o que lhes permite o tempo necessário para aprimorar o seu conhecimento - como ressalta o músico -, e não apenas consumir. Contudo, esse mesmo país em transição ainda sofre com uma elite que não aceita a voz que cresce cada vez mais nas periferias, buscando reconhecimento e o direito à cidade e à cidadania. E é ali, nas regiões periféricas, que existe hoje toda uma efervescência cultural, mas também social e política, apontando os possíveis caminhos futuros para o Brasil. Nesse contexto, elaborar políticas públicas que fomentem e aproveitem essa produção deveria ser prioridade para as autoridades governamentais. E algo a ser cobrado por todos.

A edição traz ainda uma matéria que apresenta os 65 finalistas e os seis vencedores do III Concurso Aprender e Ensinar Tecnologias Sociais, promovido pela Fórum em parceria com a Fundação Banco do Brasil. Os números mostram não apenas o sucesso da difusão do conceito em todo o Brasil, como também a conexão que tem sido possível fazer entre as tecnologias sociais e as experiências de professores que envolvem as comunidades nos entornos dos espaços educacionais.

Não é à toa que o Aprender e Ensinar foi tido pelo coordenador da Secretaria de Educação Básica do MEC, Maurício Prado, como o que alcança hoje o maior número de inscritos na área em todo o País. No total, foram 4.698 inscrições de professores que trataram do tema com seus alunos, e 1.780 deles enviaram propostas detalhadas de suas iniciativas. 0 alcance do Concurso também 
evidencia o potencial que as tecnologias sociais têm para auxiliar na superação de lacunas educacionais, promovendo a interdisciplinaridade e despertando a consciência social entre estudantes e suas famílias. (FÓRUM, março de 2013, on-line)

Como é explicitado, o contexto sociocultural da edição é de grande alcance para a sociedade brasileira que até o ano de 2013 conseguiu propiciar melhores condições de vida. Nesse sentido, é explicitada a opinião do rapper Mano Brown, capa da edição que reitera o posicionamento da revista acerca da violência que ainda assolava o país ao expor que, na tentativa de acabar com a violência, o poder acabava por agir "buscando sempre ações conservadoras e de cunho repressivo que, inevitavelmente, se voltam contra ela mesma".

Com isso, nota-se os valores sociais postos de que o corpo social, quando não privilegiado por tal proteção, submete-se à escolha de um policial como combatente da violência quando este corrobora a ação violenta. Assim, reforça-se a disparidade social vigente também, quando é exposto que a periferia não tem voz na sociedade; tais fatos revelam que a seleção temática é uma escolha social e assim valorativa, segundo a teoria bakhtiniana. Desse modo, ao optar por trabalhar com o aspecto social, a revista revela sua estilística e ideologia que perpetua.

Em diálogo com o gênero exposto na edição de Realidade, é apresentada a temática do número e como a revista conduz a temática. No entanto, em Fórum, privilegia-se uma maior discussão do que será retratado, ao trazer um breve resumo do que será referenciado ao longo das páginas. Para uma análise comparativa da edição da Fórum, a seguir, apresentamos a edição de número 168 de outubro de 2014:

O segundo turno de uma eleição é o momento de confronto de projetos, em geral, opostos em um ou muitos sentidos. A disputa presidencial de 2014 não foge à regra. Repete-se uma polarização que vem sendo a tônica no cenário nacional desde 1994, quando Fernando Henrique Cardoso se elegeu presidente da República superando Lula, segundo colocado.

No entanto, há diferenças em relação aos cenários de pleitos passados. Primeiro, o acirramento é maior e a imprevisibilidade, idem. É o tipo de contexto que não admite tergiversações ou omissões. Por isso, Fórum declara sua opção desde já.

Nossa publicação nasceu a partir do Fórum Social Mundial, em 2001, e desde então tem acompanhado e retratado as mudanças ocorridas no período. Àquela época, vivíamos sob a égide do pensamento único, que anunciava o fim da História e o triunfo do neoliberalismo. Aos poucos, a população de todo o continente e de 
outras partes do mundo foi reagindo. Nas ruas e nas urnas. Assim, subiram aos governos forças progressistas que representaram rupturas não só com o modelo econômico e social, promovendo a inclusão em diversos níveis, mas que também tiveram força simbólica para fazer com que muitos excluídos passassem a ter contato com o poder público, algo inédito até então.

De lá para cá, muitos avanços ocorreram. Mas muitos ainda estão por vir. E todos nós temos pressa. $\mathrm{O}$ atual governo tem falhas em diversas áreas, muitas delas relatadas e reportadas na Fórum. As políticas direcionadas aos povos indígenas, a tibieza diante da defesa de direitos de minorias, o ritmo da execução da reforma agrária, entre outros pontos, foram questões que estiveram presentes em nossas reportagens e artigos, e continuaremos cobrando. Mas o que se coloca agora é uma possibilidade não só de não avançarmos como de retrocedermos.

Com um Congresso mais conservador, medidas defendidas por Aécio e que afrontam os direitos humanos como a redução da maioridade penal têm ampla possibilidade de serem aprovadas. A demarcação de terras indígenas sob controle exclusivo do Congresso Nacional também é outro recuo que ganha força em face de um governo do PSDB. E o retorno de Armínio Fraga, desta vez como ministro da Fazenda, representa uma reprise de todo o cenário daqueles meados do fim do século 20 e começo do 21, quando eram mais importantes os "direitos" da banca do que das pessoas.

Em função disso, defendemos o voto em Dilma. E seguiremos em nossa posição de cobrança, sem falseamentos e nem praticando um jornalismo que se baseia em ilegalidades ou suposições, algo tão em voga na mídia tradicional. O que não é de hoje, mas que não precisa ser para sempre. (FÓRUM, on-line, 2014).

O momento histórico em que o editorial foi veiculado foi marcado pela campanha eleitoral à presidência do Brasil, mais especificamente no segundo turno, entre os candidatos Aécio Neves, representante do Partido da Social Democracia do Brasil, e Dilma Rousseff, do Partido dos Trabalhadores. Nesse contexto, o editorial evidencia qual o posicionamento do veículo diante uma situação de embate entre forças, ao colocar-se a favor da reeleição de Dilma ao afirmar "defendemos o voto em Dilma", reforçando que todo discurso é ideológico e, aqui, está explícito que a esfera jornalística também firma seu posicionamento, desconstruindo estereótipos de neutralidade do jornalismo.

Importante ressaltar que neste contexto a sociedade brasileira mostrou-se polarizada entre os ideais considerados de esquerda, defendidos por Dilma, e os de direita, representados por Aécio, o que revela a finalidade do locutor de posicionar-se e escolher por tal temática em seu editorial. Ademais, ao defender o voto na candidata do PT, notase a escolha da revista por defender os valores sociais progressistas, valorizando a busca 
por romper com as desigualdades sociais criadas pelo sistema econômico vigente. Assim, analisando as edições de Fórum, podemos notar, por meio dos aspectos estilísticos e as temáticas desenvolvidas, qual é a ideologia defendida.

Ainda, tendo em vista que nesta edição há uma defesa de posicionamento, o uso da $1^{\text {a }}$ pessoa do plural é bem marcado, o que não ocorre na edição 120, em que a revista se coloca por meio de um tom impessoal. Tal fato evidencia, assim como preconizava Bakhtin, a mudança estilística de acordo com os intuitos discursivos, o projeto de dizer em um enunciado de acordo com a função social que se busca cumprir, o que leva ao discurso a caracterização de um ato ético.

Neste editorial, a fim de persuadir, as escolhas lexicais e o discurso materializado são pautados em uma fundamentação histórica desde a criação da revista, fomentando a necessidade da discussão sobre o social e suas pluralidades, pauta não promovida pelo candidato de direita. Assim, ao tomar tais signos, apresenta um discurso de autoridade que demonstra e reitera a linha editorial do veículo, o estilo que pode ser visto nesta e nas demais edições. Ainda, verifica-se que a contextualização norteia o leitor sobre a temática que será desenvolvida ao longo da edição, aspecto que está atrelado à estrutura composicional de um editorial. Em divergência à revista Realidade, nas edições de Fórum denomina-se essa seção como editorial e o locutor é a redação da revista.

Diante de tais aspectos, podemos aferir que os gêneros discursivos editorial e carta do editor, nos diferentes momentos históricos, cumprem com o objetivo de explanar a temática central do veículo jornalístico na edição que é posta, assim há uma estabilidade e relação entre os gêneros. Ademais, há uma linguagem que privilegia a formalidade e objetividade dos fatos, tendo em vista a brevidade da exposição nesta seção. Outrossim, pode-se dizer que os enunciados têm o intuito de persuadir e convencer os leitores acerca da defesa que o suporte faz; tal fato pode ser verificado diante as escolhas lexicais realizadas ao longo do texto, materializando a função social do jornalismo de convencer seu leitor.

Em contrapartida, há instabilidades, tendo em vista o estilo que cada veículo assume. Mas, o que se mostra evidente, principalmente, é a alternância diante o momento sóciohistórico que define como um enunciado pode ser constituído, como é verificado na mudança que ocorre quando vê-se um editorial na revista em um contexto de censura das mídias, como o que acontece com a Realidade, na qual não há um posicionamento explícito, apesar de tentar deixar esclarecido na edição 6 que não concordava com a posição tomada pelo poder público. Já na revista Fórum, há uma discussão ampla e com ideologias bem marcadas, tendo em vista que se coloca em um momento de governo democrático. 


\section{Considerações finais}

A partir das postulações evidenciadas nesta breve análise, parte da pesquisa em desenvolvimento, verifica-se que o gênero editorial, representado aqui pela revista Fórum, e a carta do editor, analisada por meio da revista Realidade, apresentam estabilidades ao tratarem do posicionamento das instituições e explanarem o que será retratado na edição. Assim, seguem as especificidades pressupostas para tais gêneros. É importante ressaltar que Realidade, por meio das cartas do editor, buscava cumprir com os pressupostos da época para manter-se ativa na imprensa brasileira e por isso reitera em seus enunciados valores nacionalistas, mas que buscavam descentralizar as ideologias tradicionais comungadas na época, como foi evidenciado pela discordância apresentada na carta do editor sobre o impedimento sofrido pela revistas Do mesmo modo, Fórum, mediante os editoriais, reforça sua participação e importância social e evidencia que seus valores estão politicamente associados à valorização das questões sociais, visto as escolhas temáticas e o modo como foram abordadas as questões.

Cabe ressaltar que, em diferentes momentos sócio-históricos e em veículos distintos, a esfera jornalística reitera seu papel formador, serve como um mecanismo de esclarecimento para a sociedade quando a revista tem a necessidade de se posicionar publicamente. Os recortes apresentados evidenciam os conceitos de gênero discursivo, enunciado concreto, dialogismo e ideologia a partir das discussões bakhtinianas do discurso e refletem os pressupostos pelos estudos do jornalismo acerca dos textos opinativos.

Ademais, é possível concretizar que, diante dos preceitos bakhtinianos, as relações dialógicas com o contexto são evidentes na constituição do enunciado, assim como os aspectos estilísticos de cada veículo que caracterizam os aspectos individuais de cada suporte, mas também aspectos sociais em prol do projeto de dizer de cada edição, que contempla temas que necessitam de abordagens específicas a fim de angariar seu público-alvo. Com isso, na constituição do enunciado revelam-se as ideologias e valores comungados pelas revistas, tanto na escolha temática como na composição estilística de cada um.

Ainda sobre o público-alvo, a análise mostra-nos o processo dialógico entre o eu-outro, visto o direcionamento aos leitores que conseguem os valores comungados pelas revistas. Na análise das instabilidades, verificam-se mudanças de acordo com a alteração de público que se tem, como no caso da revista Realidade em que se tem como alvo uma sociedade que vivencia um contexto autoritário e caracteriza-se como nacionalista, o que possibilita um discurso que contemple esses aspectos na sua exposição. Já na revista Fórum, em uma conjuntura democrática, é possível notar um discurso que evidencia com mais intensidade o posicionamento da revista que tece críticas claras ao contexto, o que é visto até mesmo na explanação dos conteúdos, apresentados mais detalhadamente do que na Realidade. 
Outrossim, as instabilidades estão associadas a aspectos que constituem os enunciados assim como Bakhtin preconizava, evidenciando que apesar de ocorrer definições e finalidades específicas para cada gênero, elas se alteram na sua atuação no contexto. Tal fato revela-nos a força da linguagem nas esferas de atividade humana que, para cumprir as finalidades do momento sócio-histórico, atuam com maior ou menor intensidade por meio das palavras.

Por fim, as reflexões desteartigo contribuem para a compreensão dos gêneros jornalísticos visto o caráter formador desta esfera e sua importância, principalmente em contextos em que a discussão e o posicionamento são postos à prova e impedidos de serem esclarecidos. Desse modo, as relações dos gêneros discutidos evidenciam a motivação para posteriores indagações como analisar a recorrência dos aspectos estilísticos nos veículos e como isso se constitui de acordo com as mudanças históricas.

\section{REFERÊNCIAS}

BAKHTIN, M. Para uma filosofia do ato responsável. São Carlos: Pedro \& João, 2009.

BAKHTIN, M. Os gêneros do discurso. In: BAKHTIN, M. Estética da criação verbal. Tradução Paulo Bezerra. São Paulo: Martins Fontes, 2003. p. 261-306.

BRAIT, B. Estilo. In: BRAIT, B. (org.). Bakhtin: conceitos-chave. São Paulo: Contexto, 2005a. p. 79-102.

BRAIT, B. Enunciado/ enunciado concreto/ enunciação. In: BRAIT, B. (org.). Bakhtin: conceitos-chave. São Paulo: Contexto, 2005b. p. 61-77.

BUBNOVA, T. O que poderia significar o "Grande Tempo". Bakhtiniana, São Paulo, v. 10, n. 2, p. 05-16, mai./ago. 2015.

FIORIN, J. L. Introdução ao pensamento de Bakhtin. São Paulo: Ática, 2006.

FÓRUM. São Paulo, n. 168, 2014. Disponível em: https://revistaforum.com.br/ digital/168/editorial-dilma-segundo-turno-porque-forum-sempre-teve-lado/. Acesso em: 10 jun. 2019.

FÓRUM. Editorial n. 120, 2013. Disponível em: https://revistaforum.com.br/digital/ edicoes/120/. Acesso em: 10 jun. 2019. 
GERALDI, J. W. Heterocientificidade nos estudos linguísticos. In: GEGE. Palavras e contrapalavras: enfrentando questões da metodologia bakhtiniana. São Carlos: Pedro \& João Editores, 2012. p. 19-39.

MACHADO, I. Gêneros discursivos. In: BRAIT, B. (org.). Bakhtin: conceitos-chave. São Paulo: Contexto, 2005. p. 151-166.

MARQUES DE MELO, J. A opinião no jornalismo brasileiro. São Paulo: Vozes, 1985.

MARCHEZAN, R. C. Diálogo. In: BRAIT, B. (org.). Bakhtin: outros conceitos-chave. São Paulo: Contexto, 2006. p. 115-129.

MIOTELLO, V. Ideologia. In: BRAIT, B. (org.). Bakhtin: conceitos-chave. São Paulo: Contexto, 2005. p. 168-176.

REALIDADE, n. 1, São Paulo, 1966a.

REALIDADE, n. 6, São Paulo, 1966b.

RODRIGUES, R. H. A constituição e o funcionamento do gênero jornalístico artigo: cronotopo e dialogismo. 2001. Tese (Doutorado em Linguística Aplicada e Estudos da Linguagem) - Pontifícia Universidade Católica de São Paulo, São Paulo, 2001.

SILVA, S. S. O percurso sócio-histórico de uma tradição discursiva: da carta ao editorial. 2011. Tese (Doutorado em Línguas Vernáculas) - Faculdade de Letras, Universidade Federal do Rio de Janeiro, Rio de Janeiro, 2011.

VOLÓCHINOV, V. N. Marxismo e filosofia da linguagem: problemas fundamentais do método sociológico na ciência da linguagem. Rio de Janeiro: 34, 2017.

VOLÓCHINOV, V. N.; BAKHTIN, M. M. Discurso na vida e na arte: sobre a poética sociológica. Tradução para uso didático por Carlos Alberto Faraco e Cristovão Tezza. 